\title{
Deposição e uniformidade de distribuição da calda de aplicação em plantas de café utilizando a pulverização eletrostática
}

\author{
Deposition and distribution uniformity of spray in coffee plants using electrostatic spraying
}

\author{
Robson Shigueaki Sasaki ${ }^{I}$ Mauri Martins Teixeira' ${ }^{\mathrm{II}}$ Haroldo Carlos Fernandes ${ }^{\mathrm{II}}$ \\ Paulo Marcos de Barros Monteiro ${ }^{\mathrm{II}}$ Denílson Eduardo Rodrigues ${ }^{\mathrm{III}}$
}

RESUMO

No âmbito da tecnologia de aplicação de agrotóxicos, a pulverização eletrostática é um sistema disponível comercialmente, no entanto, pouco empregado, devido à existência de algumas divergências quanto à eficiência desse sistema, razão pela qual o entendimento dessa tecnologia e suas interações com a planta tornam-se necessários. Nesse contexto, objetivouse avaliar a utilização da pulverização eletrostática na cultura do café quanto à eficiência de deposição e a uniformidade de distribuição da calda de aplicação. Utilizou-se um pulverizador eletrostático, marca Electrostatic Spraying Systems, modelo ESS MBP 4.0. O experimento foi instalado no delineamento de parcelas subsubdivididas $(2 \times 3 \times 6)$, com dois sistemas de pulverização (sistema eletrostático ligado e desligado), três partes da planta (superior, médio e inferior) e seis posições de coleta das folhas, com quatro repetições. Quanto à uniformidade de distribuição, observou-se que houve maior variabilidade na deposição, quando o sistema eletrostático permaneceu ligado, com maior deposição na parte externa do dossel. Os valores de coeficiente de variação para o sistema eletrostático ligado e desligado foi de 40,3 e $33,08 \%$, respectivamente. O sistema eletrostático foi eficiente na pulverização em plantas de café e proporcionou aumento de $37 \%$ na deposição da calda de aplicação em relação ao sistema eletrostático desligado.

Palavras-chave: tecnologia de aplicação de agrotóxicos, cafeeiro, deposição de gotas.

\section{ABSTRACT}

In the scope of the application technology of pesticides, electrostatic spraying is a system commercially available, however, little used because there is some disagreement as to the efficiency of this system, so understanding this technology and its interactions with the plant become necessary. In this context, the aim of this study was to evaluate the electrostatic spraying on coffee as to the deposition efficiency and distribution uniformity of spray. We used an electrostatic sprayer, manufactured by Electrostatic Spraying Systems Co., model ESS MBP 4.0. The experiment was set on split plot design, $(2 \times 3 \times 6)$, with two spraying systems (electrostatic system on and off), three parts of the plant (top, medium and bottom) and six positions of leaves collection, with four replications. As for the distribution uniformity of spray, it was observed there was more variability in the deposition when the electrostatic system remained on, with higher deposition in the outer canopy. The coefficients of variation for the electrostatic system on and off were 40.3 and $33.08 \%$, respectively. The electrostatic spraying system was effective in coffee plants and increased spray deposition of $37 \%$ compared to when the electrostatic system was off.

Key words: pesticide application technology, coffee, droplets deposition.

\section{INTRODUÇÃO}

Dentre as espécies cultivadas no território brasileiro, o café destaca-se desde o período colonial como gerador de emprego e renda. O Brasil, atualmente, é o maior produtor e exportador do mundo e também o segundo maior consumidor mundial de café. No ano de 2011, o país produziu 44,3 milhões de sacas de 60kg (IBGE, 2012).

O cafeeiro é constantemente infestado por pragas e doenças, como bicho mineiro, ácaro da mancha anular, broca do café, cochonilha da raiz,

\footnotetext{
IPrograma de Pós-graduação em Engenharia Agrícola, Universidade Federal de Viçosa (UFV), Av. Peter Henry Rolfs, s/n, 36570-000, Viçosa, MG, Brasil. E-mail: robsonsasaki@yahoo.com.br. Autor para correspondência.

IIDepartamento de Engenharia Agrícola, UFV, Viçosa, MG, Brasil.

IIIDepartamento de Engenharia Elétrica, UFV, Viçosa, MG, Brasil. 
ferrugem do café, cigarras, entre outros (TOLEDO et al., 2005). Quando o cafeeiro é acometido por esses agentes, necessita de cuidados, pois provocam queda na produção e na qualidade dos frutos colhidos e, consequentemente, prejuízos aos produtores.

$\mathrm{Na}$ aplicação de agrotóxicos, devido à arquitetura do cafeeiro, tamanho da planta e densidade da copa, observam-se grandes entraves na aplicação de agrotóxicos, necessitando-se buscar novas tecnologias e/ou adaptações de técnicas de aplicações já utilizadas em outras culturas. Dentre essas tecnologias, podemos destacar o uso de sensores, controladores de seções e monitoramento das condições meteorológicas. Nesse sentido, a tecnologia de aplicação utilizando pulverizadores eletrostáticos também tem sido pesquisada (KIRK et al., 2001; KANG et al., 2004).

Diversas pesquisas têm demonstrado as vantagens da pulverização eletrostática. Avaliando a aplicação eletrostática em pimentão, DERKSEN et al. (2007) conseguiram resultados similares, empregando-se volumes de aplicação seis vezes menores do que os utilizados em tratamentos convencionais. LARYEA \& NO (2005) verificaram, na cultura da macieira, em que, dependendo das dimensões da planta, a pulverização eletrostática pode proporcionar um aumento na deposição em até 2,51 vezes, comparada à convencional. XIONGKUI et al. (2011), trabalhando em pomares, constataram aumento na deposição com o sistema eletrostático de até $50 \%$, comparado aos sistemas convencionais de pulverização.

No entanto, vale ressaltar a existência de trabalhos realizados com a pulverização eletrostática que não proporcionaram melhoria na aplicação de agrotóxicos, como os realizados por BAYER et al. (2011) na cultura do arroz, os quais verificaram menor penetração de gotas no interior da cultura e menores densidades de gotas, comparado a outros sistemas de pulverização. MAGNO JÚNIOR et al. (2011) avaliaram a pulverização eletrostática em citros e verificaram que a pulverização eletrostática não proporcionou aumento na deposição da calda de aplicação. Sendo assim, objetivou-se avaliar a pulverização eletrostática quanto à eficiência na deposição e a uniformidade de distribuição da calda de aplicação em plantas de café.

\section{MATERIAL E MÉTODOS}

Antes de se iniciar o ensaio de campo, caracterizou-se o pulverizador, em condições de laboratório, quanto ao espectro de gotas proporcionadas $\left(\mathrm{Dv}_{0,1} ; \mathrm{Dv}_{0,5}, \mathrm{Dv}_{0,9}\right.$, índice Span e $\%$ de gotas abaixo de $100 \mu \mathrm{m})$ com o auxílio de um analisador de partículas (Spraytech, Malvern Instruments Co). Posteriormente, prosseguiram-se as pulverizações de campo.

O ensaio foi realizado em um cafezal, cultivado com espécies de Coffea arábica L., pertencente ao Departamento de Engenharia Agrícola, setor de tratamento de águas residuais, da Universidade Federal de Viçosa, Viçosa - MG, no mês de agosto de 2011. As plantas de café possuíam altura média de $1,8 \mathrm{~m}$, diâmetro de copa médio de $1,42 \mathrm{~m}$ e distância entre linhas de 2,2m. O teor de água do solo no local do experimento foi de $0,14 \mathrm{~g} \mathrm{~g}^{-1}$.

Foi utilizado um pulverizador eletrostático, marca Electrostatic Spraying Systems, modelo ESS MBP 4.0, com capacidade do tanque de 15L. Esse pulverizador utiliza-se do princípio pneumático para a formação e o fracionamento de gotas, além de utilizar o método de indução de cargas indireto para a eletrificação das gotas.

Em campo, ajustou-se a vazão do equipamento para $0,2 \mathrm{~L} \mathrm{~min}^{-1}$ e realizou-se a calibração para se aplicar um volume de pulverização de $100 \mathrm{~L} \mathrm{ha}{ }^{-1}$. Em todas as pulverizações, o motor do pulverizador foi regulado na aceleração máxima e esperou-se o tempo de 15 s até a entrada em regime do eixo motor. Uma vez atingida a rotação de regime, realizou-se a pulverização, considerando dois métodos: 1- Sistema eletrostático ligado e 2- sistema eletrostático desligado.

Antes de se proceder às pulverizações, com a adição de corante à calda, fez-se a calibração para a solução padrão. No momento das pulverizações, as condições ambientais foram monitoradas e permaneceram com a velocidade do ar entre 0,1 a $0,7 \mathrm{~m} \mathrm{~s}^{-1}$, umidade relativa acima de $60 \%$ e temperatura do ar entre 26 a $29^{\circ} \mathrm{C}$. As pulverizações foram realizadas somente no lado da planta referente à face leste e adotado, como superfície amostradora, as folhas do cafeeiro.

$\mathrm{Na}$ coleta das folhas, tomou-se como referência a face leste da planta, voltada para a rua, entre as linhas de plantio, dividindo-a em três partes (superior, médio e inferior) e cada parte da planta foi subdividida em seis posições denominadas de P1, P2, P3, P4, P5 e P6. A posição P1, P2 e P3 estavam voltadas para a face leste, em que $\mathrm{P} 1=$ posição externa do dossel da planta, P2 = posição a $0,2 \mathrm{~m}$ em relação à parte externa $(\mathrm{P} 1)$ e $\mathrm{P} 3$ = posição a $0,4 \mathrm{~m}$ em relação à parte externa $(\mathrm{P} 1)$. Já as posições $\mathrm{P} 4$, P5 e P6 estavam voltadas para a face oeste, em que P6 = parte externa do dossel; P5 = posição a 0,2m em relação à P6 e P4 = posição a 0,4m de P6 (Figura 1). 


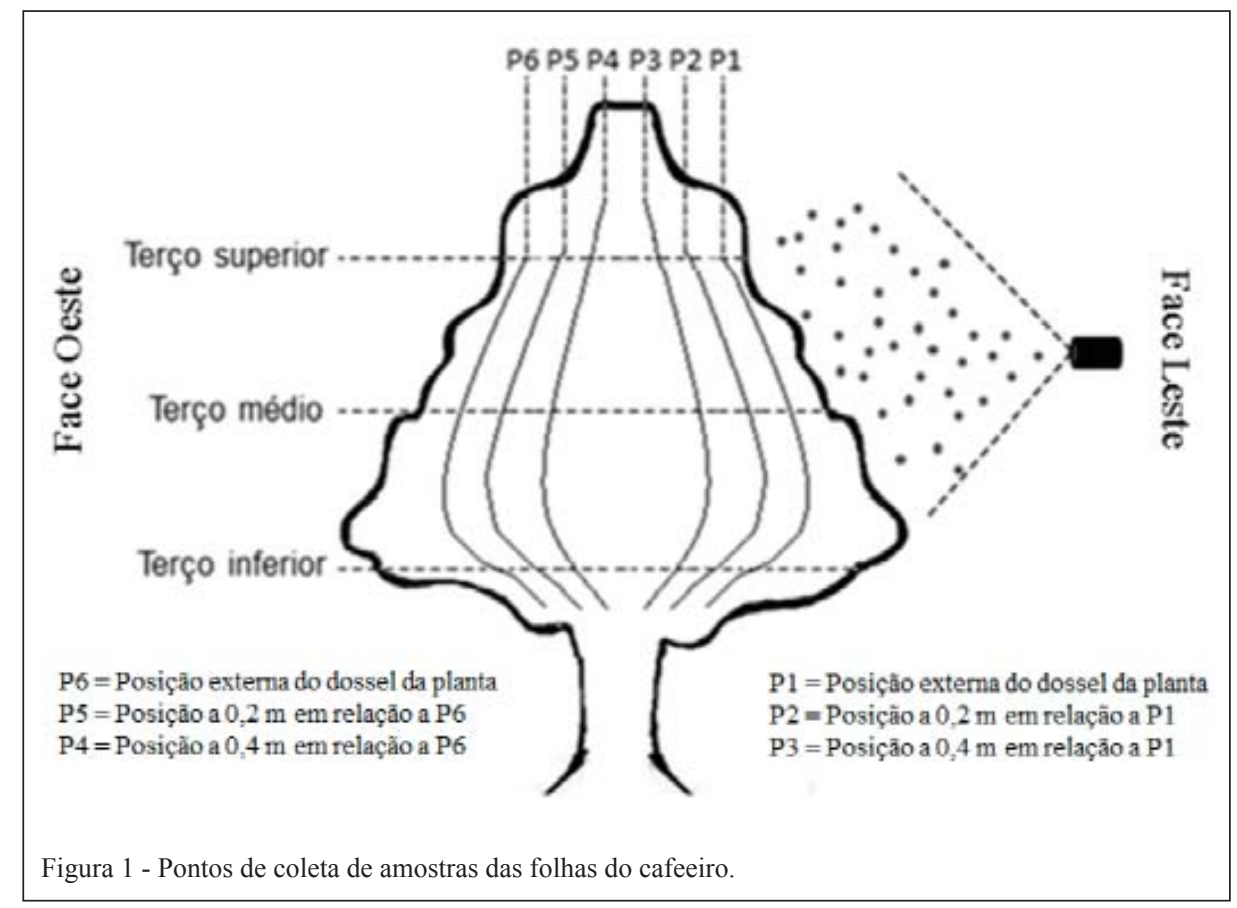

O experimento foi conduzido em esquema de parcelas subsubdivididas, sendo que as parcelas foram consideradas os dois sistemas de pulverização, nas subparcelas as três partes da planta e nas subsubparcelas as seis posições de coleta das folhas, com quatro repetições, totalizando 144 unidades experimentais. A fim de se minimizarem os erros e aumentar as leituras de absorbância no espectrofotômetro, a cada ponto amostral, coletaramse duas folhas.

As folhas coletadas foram acondicionadas em sacos plásticos, lavadas em $50 \mathrm{~mL}$ de água destilada e determinadas as absorbâncias no espectrofotômetro. Após serem lavadas, as folhas foram digitalizadas, com o auxílio de uma câmera fotográfica, marca Sony, modelo HX-1, com resolução de 9 mega pixel. Posteriormente, com o auxílio do software para análises de imagens, ImageTools 3.0, determinou-se a sua área $\left(\mathrm{cm}^{2}\right)$. Em seguida, determinou-se a deposição do corante por unidade de área, conforme a metodologia proposta por PALLADINI (2000), utilizando-se como traçador o corante Azul Brilhante na diluição de $3 \mathrm{~g} \mathrm{~L}^{-1}$. Os dados foram submetidos à analise de variância pelo teste $\mathrm{F}(\mathrm{P}<0,05)$ e as médias comparadas pelo teste Tukey $(\mathrm{P}<0,05)$, com o auxílio do software estatístico Sisvar, versão 5.3.

\section{RESULTADOS E DISCUSSÃO}

A caracterização do pulverizador indicou que os diâmetros das gotas produzidas foram considerados pequenos. Os valores de $\mathrm{Dv}_{0,1}, \mathrm{Dv}_{0,5}$, $\mathrm{Dv}_{0,9}$ foram de 19,3; 57,0 e 169,8 $\mu \mathrm{m}$, respectivamente, e o índice Span 2,66. Quanto ao percentual de gotas com diâmetro abaixo de $100 \mu \mathrm{m}$, obtiveram-se valores médios da ordem de $60 \%$.

Dessa forma, em uma pulverização, o emprego de gotas com diâmetros reduzidos possibilita uma melhor dispersão das gotas sobre a superfície foliar, aumentando a densidade de gotas depositadas no alvo e a redução do volume de calda a ser aplicado por unidade de área. Em se tratando da pulverização eletrostática, quanto menor o diâmetro da gota mais fácil de carregá-las, entretanto, gotas de tamanho reduzido, em condições de baixa umidade relativa e altas temperaturas, podem sofrer a evaporação (VILLALBA \& HETZ, 2010). Vale ressaltar que gotas pequenas apresentam elevado risco de deriva, pois são mais propensas a se afastarem da zona de aplicação do que as gotas maiores (KIRK, 2007).

$\mathrm{Na}$ avaliação da eficiência de deposição da calda de aplicação, considerando a planta como um todo, verificou-se que o sistema eletrostático proporcionou aumento de $37 \%$ na deposição em relação ao sistema eletrostático desligado (Tabela 1). Esses resultados 
Tabela 1 - Média da deposição da calda de aplicação $\left(\mu \mathrm{L} \mathrm{cm}^{-2}\right)$ na planta do cafeeiro.

\begin{tabular}{lc}
\hline Sistema eletrostático & Deposição de calda $\left(\mu \mathrm{L} \mathrm{cm}^{-2}\right)$ \\
\hline Ligado & $0,59 \mathrm{a}$ \\
Desligado & $0,43 \mathrm{~b}$ \\
\hline
\end{tabular}

Médias seguidas por uma mesma letra não diferem entre si, a 5\% de probabilidade pelo teste de F.

foram semelhantes aos obtidos por LARYEA \& NO (2005) e por XIONGKUI et al. (2011).

$\mathrm{Na}$ avaliação da uniformidade de distribuição da calda de aplicação na planta de café, houve uma maior variabilidade na deposição quando o sistema eletrostático permaneceu ligado, o qual apresentou coeficiente de variação de 40,3\%. No entanto, quando o sistema eletrostático foi desligado, o valor do coeficiente de variação reduziu para 33,08\%.

Ao se realizar o estudo da deposição, considerando todos os fatores (sistema de pulverização, parte da planta e posições de coleta das folhas), houve interação somente entre o sistema de pulverização e a posição de coleta das folhas (Tabela 2).

Ao se avaliar essa interação, verificou-se que, com o sistema eletrostático ligado, as maiores deposições ficaram na posição externa do dossel. Por outro lado, quando o sistema foi desligado, houve redução na deposição da calda de aplicação, no entanto, houve a tendência de se homogeneizar a distribuição da calda ao longo da planta, o que explica a redução nos valores do coeficiente de variação, já mencionada (Tabela 3).

As maiores deposições na posição externa do dossel (P1) com o sistema eletrostático ligado podem ter ocorrido pelo fato de que, quando se tem um objeto eletrizado (gota), este tende a se descarregar em um corpo aterrado o mais próximo possível, neste caso, a parte externa do dossel. Esses resultados corroboram os obtidos por ALMEKINDERS et al. (1992).

Em uma pulverização em campo, o objetivo é que a distribuição da calda de aplicação seja o mais uniforme possível na planta. No entanto, isso nem sempre é possível, principalmente quando se trata de plantas arbóreas com elevada densidade foliar. Os resultados deste trabalho demonstram que a pulverização eletrostática pode ser uma alternativa ao produtor. As deposições da calda de aplicação, considerando as posições estudadas, foram maiores em relação ao sistema eletrostático desligado.

\section{CONCLUSÃO}

O sistema eletrostático foi eficiente na pulverização em plantas de café. A pulverização eletrostática proporcionou incremento na deposição de calda de $37 \%$. A uniformidade de distribuição de calda foi maior ao se utilizar o sistema eletrostático desligado.

Tabela 2 - Resumo da análise de variância.

\begin{tabular}{|c|c|c|c|}
\hline Fonte de variação & Graus de liberdade & Soma de quadrados & Quadrado médio \\
\hline Blocos & 3 & 0,2718 & $0,0906^{*}$ \\
\hline A- Sistema de pulverização & 1 & 0,95358 & $0,95358^{*}$ \\
\hline Resíduo A & 3 & 0,02483 & \\
\hline Parcelas & 7 & 1,25021 & \\
\hline B- Partes da planta & 2 & 0,31467 & $0,015733^{*}$ \\
\hline Interação AxB & 2 & 0,02699 & $0,0135^{\mathrm{ns}}$ \\
\hline Resíduo B & 12 & 0,24192 & \\
\hline Subparcelas & 23 & 1,8338 & \\
\hline C- Posições de coleta & 5 & 1,90647 & $0,38129^{*}$ \\
\hline Interação AxC & 5 & 0,32518 & $0,06504^{*}$ \\
\hline Interação BxC & 10 & 0,19837 & $0,01984^{\mathrm{ns}}$ \\
\hline Interação $\mathrm{AxBxC}$ & 10 & 0,15213 & $0,01521^{\mathrm{ns}}$ \\
\hline Resíduo C & 90 & 2,0748 & \\
\hline Total & 143 & 6,49074 & \\
\hline
\end{tabular}

${ }^{*}$ Significativo a $5 \%$ de probabilidade pelo teste $\mathrm{F}$.

${ }^{\text {ns }}$ Diferença não significativa. 
Tabela 3 - Média das deposições da calda de aplicação $\left(\mu \mathrm{L} \mathrm{cm}{ }^{-2}\right)$ em diferentes sistemas de pulverização e posições na planta de café.

\begin{tabular}{|c|c|c|c|c|c|c|}
\hline \multirow[t]{2}{*}{ Sistema Eletrostático } & \multicolumn{3}{|c|}{------------------------'Face Leste-------------------------- } & \multicolumn{3}{|c|}{-----Face Oeste------- } \\
\hline & $\mathrm{P} 1$ & $\mathrm{P} 2$ & P3 & P4 & P5 & P6 \\
\hline Ligado & $0,84 \mathrm{aA}$ & $0,71 \mathrm{aAB}$ & $0,62 \mathrm{bB}$ & $0,42 \mathrm{aC}$ & $0,41 \mathrm{aC}$ & $0,57 \mathrm{aBC}$ \\
\hline Desligado & $0,51 \mathrm{bB}$ & $0,50 \mathrm{bA}$ & $0,53 \mathrm{bA}$ & $0,35 \mathrm{aAB}$ & $0,32 \mathrm{aB}$ & $0,38 \mathrm{bAB}$ \\
\hline
\end{tabular}

Médias seguidas por uma mesma letra, maiúscula na linha e minúscula na coluna, não diferem entre si a 5\% de probabilidade pelo teste de Tukey.

\section{REFERÊNCIAS}

ALMEKINDERS, H. et al. Spray deposit patterns of an electrostatic atomizer. Transactions of the ASAE, Saint Joseph, v.35, n.5, p.1361-1367, 1992. Disponível em: <http://agris.fao.org/agrissearch/search/display.do?f=1993/US/US93077.xml;US9332935>. Acesso em: 05 mar. 2012.

BAYER, T. et al. Equipamentos de pulverização aérea e taxas de aplicação de fungicida na cultura do arroz irrigado. Revista Brasileira Engenharia Agrícola Ambiental, Campina Grande, PB, v.15, n.2, p.192-198, 2011. Disponível em: <http://www.scielo.br/ pdf/rbeaa/v15n2/v15n2a07.pdf $>$. Acesso em: 5 mar. 2012.

DERKSEN, R.C. et al. Field evaluation of application variables and plant density for bell pepper pest management. Transactions of the ASAE, St. Joseph, v.50, n.6, p.1945-1953, 2007. Disponível em: $<$ https://kb.osu.edu/dspace/bitstream/handle/1811/49141/fac_BennettM TransactionsoftheASABE_2007_50_6.pdf?sequence=3>. Acesso em: $\overline{5}$ mar. 2012.

KANG, T.G. et al. Spray and depositional characteristics of electrostatic nozzles for orchard sprayers. Transaction of the ASAE, St. Joseph, v.41, n.5, p.21-28, 2004. Disponível em: $<$ https://elibrary.asabe.org/abstract.asp?aid=16122\&t=1 $>$. Acesso em: 5 mar. 2012.

KIRK, I.W. et al. Aerial electrostatic spray system performance. Transactions of the ASAE, St. Joseph, v.44, p.1089-1092, 2001. Disponível em: <http://ddr.nal.usda.gov/bitstream/10113/16759/1/ IND23317625.pdf>. Acesso em: 5 de mar. 2012.

KIRK, I.W. Measurement and prediction of atomization parameters from fixed-wing aircraft spray nozzles. Transactions of the ASABE, St. Joseph, v.50, p.693-703, 2007. Disponível em: $<$ http://ddr.nal.usda.gov/bitstream/10113/10736/1/IND44014768. pdf>. Acesso em: 5 de mar. 2012.

LARYEA, G.N.; NO, S.Y. Effect of fan speed and electrostatic charge on deposition of orchard canopy sprays. Atomization and
Sprays, Redding, v.15, p.133-144, 2005. Disponível em: <http:// www.begellhouse.com/journals/6a7c7e10642258cc,55bbbfd80d2 8acda,0228d8140149fd66.html>. Acesso em: 5 de mar. 2012. doi: 10.1615/AtomizSpr.v15.i2.

MAGNO JÚNIOR, R.G. et al. Desenvolvimento de um dispositivo eletrônico para atração de gotas da aplicação eletrostática em plantas cítricas. Bioscience Journal, Uberlândia, v.27, n.5, p.798-804, 2011. Disponível em: <http://www.seer.ufu.br/index. php/biosciencejournal/article/view/11647>. Acesso em: 5 mar. 2012 .

IBGE (INSTITUTO BRASILEIRO DE GEOGRAFIA E ESTATÍSTICA). Confronto das safras de 2011 e 2012 - Brasil, 2012. Disponível em: <http://www.ibge.gov.br/home/estatistica/ indicadores/agropecuaria/lspa/lspa_201208_5.shtm>. Acesso em: 17 set. 2012.

PALLADINI, L.A. Metodologia para avaliação da deposição em pulverizações. 2000. 111f. Tese (Doutorado em Agronomia) - Universidade Estadual Paulista, Botucatu, SP.

VILLALBA, J.; HETZ, E. Deriva de productos agroquímicos Efecto de las condiciones ambientales. In:___. Tecnología de aplicación de agroquímicos. Argentina: Área de comunicaciones del INTA Alto Valle, 2010. Cap.3, p.45-54.

TOLEDO, M.A. et al. Pragas-chave do cafeeiro das regiões da Alta Mogiana, Cerrado de Minas Gerais e do Espirito Santo. In: CONGRESSO BRASILEIRO DE PESQUISAS CAFEEIRAS, 31., 2005, Guarapari. Trabalhos apresentados... Rio de Janeiro: MMA/SRD/PROCAFÉ/PNFC, 2005. p.379-380.

XIONGKUI, H. et al. Precision orchard sprayer based on automatically infrared target detecting and electrostatic spraying techniques. International Journal of Agricultural and biological engineering, Beijing, v.4, p.35-40, 2011. Disponível em: <http://www.ijabe.org/index.php/ijabe/article/ view/393>. Acesso em: 5 mar. 2012. doi: 10.3965/j.issn.19346344.2011.01.035-040. 